\title{
Effects of different surface treatments on the shear bond strength of veneering ceramic materials to zirconia
}

\author{
Adil Othman Abdullah'1 ${ }^{1}$ Yu Hui ${ }^{2}$, Xudong Sun², Sarah Pollington ${ }^{3}$, Fenik Kaml Muhammed ${ }^{1}$, Yi Liu' ${ }^{1 *}$ \\ ${ }^{1}$ School and Hospital of Stomatology, China Medical University, Shenyang, Liaoning Province, PR China \\ ${ }^{2}$ School of Environmental and Chemical Engineering, Dalian University, Dalian, Liaoning Province, PR China \\ ${ }^{3}$ School of Clinical Dentistry, the University of Sheffield, Sheffield, United Kingdom
}

\begin{abstract}
PURPOSE. To evaluate and compare the effect of different materials and techniques on the shear bond strength of veneering ceramic materials to zirconia. MATERIALS AND METHODS. 136 sintered zirconia cubes were prepared and randomly divided into four study groups according to corresponding methods of surface treatment and materials: GLN (grinding followed by laser scanning using Noritake Cerabien ZR), SLN (sandblasting followed by laser scanning using Noritake Cerabien ZR), GLV (grinding followed by laser scanning using VITA VM 9), and SLV (sandblasting followed by laser scanning using VITA VM 9). Spraying technique was performed to coat the core. Profilometer, SEM, XRD, EDS, universal testing machine, and stereomicroscope were used to record surface roughness $R a$, surface morphology, phase transformation, elemental compositions, shear bond strength SBS values, and failure types, respectively. Specimens were investigated in unaged (not immersed in artificial saliva) and aged (stored in artificial saliva for a month) conditions to evaluate SBS values. RESULTS. Grinding and GLN as first and second surface treatments provided satisfactory Ra values in both conditions (1.05 $\pm 0.24 \mu \mathrm{m}, 1.30 \pm 0.21 \mu \mathrm{m})$ compared to sandblasting and other groups $(P<.05)$. The group GLN showed the highest SBS values in both conditions $(30.97 \pm 3.12 \mathrm{MPa}, 29.09 \pm 4.17 \mathrm{MPa})$, while group SLV recorded the lowest $(23.96 \pm 3.60 \mathrm{MPa}, 22.95 \pm 3.68 \mathrm{Mpa})(P<.05)$. Sandblasting showed phase transformation from $\mathrm{t}-\mathrm{m}$. Mixed failure type was the commonest among all groups. CONCLUSION. GLN showed to be a reliable method which provided satisfactory bond strength between the veneer ceramic and zirconia. This method might preserve the integrity of fixed dental crowns. [J Adv Prosthodont 2019;11:65-74]
\end{abstract}

KEYWORDS: Zirconia; Veneer ceramic; Surface treatment; Laser scanning; Shear bond strength

\section{INTRODUCTION}

All-ceramic fixed crown restorations are a popular patient

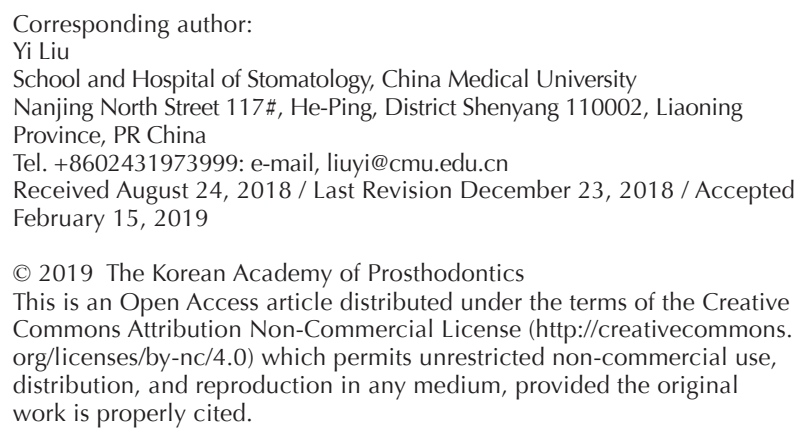

This research was supported by the Liaoning Provincial Universities and Colleges Co-cultivation Postgraduate Project (115-3110617005). choice due to the aesthetic properties similar to the natural teeth. ${ }^{1}$ For zirconia, the improved mechanical properties including strength and the physical properties such as its color similar to human teeth make the material more predominant than other ceramics in diverse research fields, in particular, various dental applications. ${ }^{2}$ Under room temperature, the material is stable and zirconium oxide is the main crystalline content. ${ }^{3}$ In load bearing areas of the mouth, it provides a higher success rate than other ceramics, in particular compared to silica-based systems. ${ }^{4}$ The material known as tetragonal zirconia polycrystal TZP, which is a polymorphic material, is presented in diverse forms based on crystal arrangements such as tetragonal (t), cubic (c), and monoclinic $(\mathrm{m}) .{ }^{5}$ Combining certain metal oxides such as yttrium, magnesium, and calcium oxides with zirconia could optimize the crystalline property of the material. ${ }^{6}$ Currently, researchers are focusing on yttrium tetragonal zirconia poly- 
crystal (Y-TZP).

Certain properties such as physico-mechanical properties could be influenced by surface treatment of the material. ${ }^{7}$ Previous literature has reported different outcomes relating to micromechanical retention following various surface treatments such as grinding, sandblasting, glazing, chemical etching, chemical vapour deposition, heat treatment, laser scanning, and liner applications. ${ }^{8-10}$ Maintaining adequate bond strength between zirconia and its corresponding veneer ceramic could be considered as a primary goal to provide longer life of all-ceramic fixed partial dentures in the oral environment under various occlusal forces. $^{11}$

Studies have reported chipping issues at the core-veneer interface after surface treatment of zirconia as a common frequent reason of failure. ${ }^{5}$ Different chipping rates have been reported in previous literature based on different time scales; for 3, 5, and 10 years, it has been reported that the chipping rate was $0 \%, 2.5 \%$ and $8-10 \%$, respectively. ${ }^{12}$ In a clinical study, this phenomenon recorded higher percentage such as $15,15.2$, and $25 \%$ in 24,30 , and 60 months interval, respectively. ${ }^{13}$ Another study has reported $0-88.9 \%$ chipping rate in one- to eight-year follow-up. ${ }^{14}$ There are several factors that play a pivotal role that may cause chipping potential, including inadequate bond strength between coreveneer ceramic, thickness ratio of core/veneer materials, thermal mismatch between core-veneer interface, the impact of firing shrinkage, and insufficient core material design. ${ }^{5,13,15}$

In recent years, studies have investigated other sophisticated methods to optimize zirconia surface treatment including laser scanning. ${ }^{6,16}$ In the last few decades, this method has become popular and has been applied to the zirconia surface to improve the accuracy, high efficiency, and strong controllability. ${ }^{16}$ The topography formed by laser depends upon certain parameters, such as power input, energy, pulse length and properties of the target material. ${ }^{16}$ Among laser systems, the following laser types are commonly used for surface treatments: Er:YAG, Nd:YAG, and $\mathrm{CO}_{2}$ laser, with differing outcome. ${ }^{17}$ For ceramic surface treatment, it has been argued that the $\mathrm{CO}_{2}$ laser is one of the preferred methods due to the sufficient absorption of the emitted wavelength by material. ${ }^{18}$ It has also been reported that the $\mathrm{CO}_{2}$ laser could optimize surface roughness of the Y-TZP material through different output powers. ${ }^{19}$

To date, there is little information on the impact of laser scanning on the bond strength between zirconia and veneer ceramic materials, and the bond strength between the two materials is still the point of concern. Thus, the purpose of this study was to investigate the impact of different surface treatments such as grinding and sandblasting followed by laser scanning on the shear bond strength between the two materials. Two hypotheses were tested in this study. The first was that sandblasting following laser scanning could not provide a better bond strength between the core and the corresponding veneers. The second was hypothesized that there is no difference between veneer ceramic materials used in this study in terms of providing an adequate bond with the core material.

\section{MATERIALS AND METHODS}

The standard compositions of Zenostar $\mathrm{T}$ zirconia core, VITA VM 9 and Noritake Cerabien ZR materials are summarized in Table 1.

Regarding preparation of the zirconia specimens, a hundred and thirty six Y-TZP zirconia cubes (Zenostar T, Wieland Dental, Technik GmbH and Co. KG, Ivoclar Vivadent, Pforzheim, Germany) were prepared by milling through computer-aided design/computer- aided manufacturing (CAD/CAM) machine (CoriTec-245i, imes-icore in CNC \& Dental Solutions GmbH, Eiterfeld, Germany).

All cubes were densely sintered in a furnace (Austromat, Dekema, Dental Keramiköfen GmbH, Freilassing, Germany) according to the manufacturer's instruction. The dimensional change that occurred was approximately $20.0 \mathrm{vol} \%$ in each specimen and the size of each specimen was finally set at $10 \times 10 \mathrm{~mm}$. The surfaces of specimens were then polished using the Zenostar T polishing set (Wieland Dental, Technik and Co. KG, Ivoclar Vivadent, Pforzheim, Germany). All specimens were ultrasonically cleaned in an ethanol solution using a digital ultrasonic cleaner (Jeken, PS-20A, Shenzhen, China) for 10 minutes and dried using an electric

Table 1. Ceramic materials used in this study

\begin{tabular}{|c|c|c|c|c|}
\hline Materials & Type of materials & Chemical composition & Manufacturer name & Lot number \\
\hline Zenostar T & $\begin{array}{l}\text { Translucent, Yttria tetragonal } \\
\text { zirconia polycrystal (Y-TZP), } \\
\text { ceramic core material }\end{array}$ & $\begin{array}{c}\mathrm{ZrO}_{2}, \mathrm{HfO}_{2}, \mathrm{Y}_{2} \mathrm{O}_{3}, \mathrm{Y}_{2} \mathrm{O}_{2}, \mathrm{HFO}_{2}, \\
\text { Aluminum oxide, and other oxides }\end{array}$ & $\begin{array}{l}\text { Ivoclar Vivadent, Wieland } \\
\text { Dental+Technik, GmbH \& Co. } \\
\text { KG, Pforzheim, Germany }\end{array}$ & V06632 \\
\hline Noritake Cerabien ZR & $\begin{array}{c}\text { Feldspar } \\
\text { veneer ceramic }\end{array}$ & $\begin{array}{c}\mathrm{SiO}_{2}, \mathrm{Al}_{2} \mathrm{O}_{3}, \mathrm{Na}_{2} \mathrm{O}, \mathrm{CaOK}_{2} \mathrm{O}, \mathrm{MgO} \\
\mathrm{LiO}_{2}, \mathrm{~B}_{2} \mathrm{O}_{3} \text {, and pigments }\end{array}$ & $\begin{array}{l}\text { Noritake Dental supply Co., } \\
\text { Nagoya, Japan }\end{array}$ & DSEXO \\
\hline VITA VM 9 & $\begin{array}{c}\text { Feldspar } \\
\text { veneer ceramic }\end{array}$ & $\begin{array}{c}\mathrm{SiO}_{2}, \mathrm{Al}_{2} \mathrm{O}_{3}, \mathrm{~K} \mathrm{~K}_{2} \mathrm{O}, \mathrm{Na}_{2} \mathrm{O}, \mathrm{Li} \mathrm{O}_{2} \mathrm{O}, \mathrm{BaO} \\
\mathrm{Fe}_{2} \mathrm{O}_{3}, \mathrm{CaO}, \mathrm{Tb}_{4} \mathrm{O}_{2}, \mathrm{MgO}, \mathrm{CeO}_{2} \\
\mathrm{P}_{2} \mathrm{O}_{5}, \mathrm{TiO}_{2}, \text { and } \mathrm{B}_{2} \mathrm{O}_{3}\end{array}$ & $\begin{array}{c}\text { Vita Zahnfabrik, Bad Säckingen, } \\
\text { Germany }\end{array}$ & 58940 \\
\hline
\end{tabular}


heat blast oven (Model DGG-9240B, Nanjing, China) for 5 minutes prior to surface treatment. All cubes were assigned to the corresponding groups as mentioned previously.

The first surface treatment was performed using a grinding method. The specimens in this group were ground under wet conditions. A dental lab micro motor engine (Model SD-A60, E-Type, Stardent Equip Co., Ltd., Foshan, China) with a rotation of 20000 rotations per minute and medium grit ceramic bur (No. SDH101G, size $22 \times 4.2 \mathrm{~mm}$, Youdent Rotary Instrument Co., Ltd, Zhenjiang, China) was used. A gentle stroking motion was applied on the core material during grinding to minimize pressure on the surface to avoid high heat generation. The rest of specimens were subjected to a sandblasting technique using $125 \mu \mathrm{m}$ alumina particles (Refo Model, Zhuhai Refine Equipment Co., Ltd., Qianshan, China) for 15 seconds at the pressure level of $2.5 \mathrm{bar}$ and the working distance was set as $10 \mathrm{~mm}$. The direction of the sandblasting was perpendicular to the specimens' surface. An identical process was followed for all specimens to standardize the method.

To perform the second surface treatment, a uniform thin layer of the veneer ceramic material was deposited on the core material using an airbrush spraying gun technique prior to conducting laser scanning. The surface of the zirconia specimens was coated with VITA VM 9 Base Dentine Shade 3M2 $(\mathrm{n}=68)$ or Noritake Cerabien ZR $(\mathrm{n}=68)$ veneer ceramic materials based on the assigned groups.

The veneer ceramic powder was weighed using a digitalized analytical balance (Sartorius Entris Analytical Balance, Göttingen, Germany) and mixed with the corresponding liquid following the manufacturer's instructions. A mini magnetic stirrer (SH-II-2, Huanghua Faithful Instrument Co., Ltd., Cangzhou, China) was used to achieve a homogenous mixture. The spraying process was then performed using the airbrush spraying gun (Dual action airbrush, Sheng, Model HS-35, Zhejiang, China). The main parameters of spraying technique included $1.5 \mathrm{~g}$ powder and 1.5 $\mathrm{mL}$ liquid as a mixture, using a mini-magnetic stirrer with 350 rotations per minute for 10 minutes, nozzle diameter of
$0.3 \mathrm{~mm}$, and working pressure of $3 \mathrm{bar}$. The total spraying time was 12 seconds and the fixed distance was set at $15 \mathrm{~cm}$ between the nozzle tip and the core surface using a special holder. The specimens were placed on a flat surface to achieve a uniform coated layer of veneer ceramic on the core material.

The second surface treatment of cores was carried out using laser scanning with a $\mathrm{CO}_{2}$ laser (Julong laser machine JL-K6040, Laser engraving, Shandong, China). The summary of the laser parameters and properties are presented in Table 2.

The specimens were divided as following for the first and second surface treatments: grinding $(\mathrm{n}=68)$ and sandblasting specimens $(n=68)$, respectively. Then specimens were subjected to the spraying technique to deposit a thin veneer ceramic layer on the core material. The second surface treatment was conducted following laser scanning for all of the specimens after transferring the specimens onto the flat X-Y laser table. The specimens were arranged as GLN, SLN, GLV, and SLV ( $\mathrm{n}=34$ each group), then the specimens were left at room temperature to cool down slowly.

Analysis of the surface roughness was conducted so that in each group, seventeen specimens were randomly selected and their surface roughness $R a$ values were recorded. To evaluate the coating on the core material, the specimens were randomly selected after performing the first surface treatment. The $\mathrm{R} a$ was measured using a profilometer (Surtronic 25, Taylor Hobson Ltd., Leicester, UK). Ra, which represents arithmetical mean roughness, was determined to indicate the $R a$ of the core. For each new specimen, recalibration was conducted using a standard core specimen $(6$ $\mu \mathrm{m})$ that was provided by the manufacturer. The cutoff length $0.08 \mathrm{~mm}$ was determined according to recommended ISO 4288 (1996). ${ }^{20}$ In each group, half of the specimens were positioned on a flat surface to measure the $R a$ values. For each of the core specimens, four readings of surface roughness were recorded and the mean value was calculated.

$\mathrm{X}$-ray diffraction was performed to detect phase trans-

Table 2. Typical laser scanning parameters and laser properties

\begin{tabular}{lccc}
\hline Laser Parameters & Value & Laser Properties & Value \\
\hline Scanning speed & $35 \mathrm{~mm} \mathrm{~s}^{-1}$ & Laser type & $\mathrm{CO}_{2}$ laser \\
Output power & $25 \mathrm{Watt}$ & Wavelength & $10.6 \mathrm{\mu m}$ \\
Distance between laser tube and the core & $15 \mathrm{~mm}$ & Frequency & $50 \mathrm{~Hz}$ \\
Space between scanned lines & $0.5 \mathrm{~mm}$ & Laser tube diameter & $8 \mathrm{~mm}$ \\
Scanning duration & 65 seconds & Spot size & $0.2 \mathrm{~mm}$ \\
& & Intensity & $0-1.6 \times 10^{6} \mathrm{~W} / \mathrm{cm}^{2}$ \\
& & Pulse length & $10-50 \mu \mathrm{\mu s}$ \\
& & Pulse energy & $150 \mathrm{~W}$ \\
\end{tabular}


formation. Phase components were identified using SmartLab X-ray diffractometer (Rigaku SmartLab, Rigaku Corporation, Tokyo, Japan) with $\mathrm{CuK} \alpha$ radiation at $200 \mathrm{~mA}$ and $40 \mathrm{kV}$. Diffraction data was collected within the $2 \theta$ range of $20-90^{\circ}$ at a step size of $0.02^{\circ}$ and a step time of 8 minutes. The peaks were read using MDI Jade v6.0, CA, USA software program to identify peaks and phases. The peak patterns were drawn using the OriginPro 2016 (OriginLab v.93E, Northampton, MA, USA) software program. The patterns were plotted by a set of line positions $2 \theta$ deg against intensity (arbitrary units).

Scanning electron microscopy (SEM) and energy dispersive spectroscopy (EDS) were undertaken. The coated core material of each group ( $\mathrm{n}=4)$ was investigated after random selection ( $\mathrm{n}=2$ interface, $\mathrm{n}=2$ top surface) through SEM (Ultra plus ZEISS, Oberkochen, Baden-Württemberg, Germany) equipped with EDS. The specimens, which were randomly selected to be investigated at the interface, were sliced to the desired shape using a slow controlled-speed diamond saw machine (Sherline 5410, Sherline products, Inc. Vista, CA, USA) under water coolant. The interface of the specimens was polished with $\mathrm{SiC}$ grit sizes \#600 and \#800 on a flat surface under running water. The core specimens were gold-sputtered using a sputter coater machine (JS-1600, Beijing HTCY Co. Ltd., Beijing, China). The specimens were then examined under different magnifications through SEM. The spot and line EDS spectra were then recorded and analyzed.

The procedure of cylindrical veneer ceramic fabrication was followed for the prepared specimens. Randomly selected specimens for each group $(\mathrm{n}=30)$ were ultrasonically cleaned in ethanol solution for 10 minutes and dried using an electric heat blast oven. A silicon mold was fabricated from polyvinyl siloxane impression material, which was used as a guide for preparing the cylindrical veneer ceramic shape as a standard. Based on each group, the powder of each veneer ceramic material was mixed with the corresponding liquid in the recommended ratio following the manufactur- er's instructions. The mixture of veneer ceramic slurry was condensed into the silicon mold through a pre-made cylindrical hole ( $5 \mathrm{~mm}$ in diameter, $3 \mathrm{~mm}$ in height) to fabricate a cylindrical veneer ceramic at the center of the core material. A lubricating agent (Marbocote 220, Mühlmeier GmbH \& Co. KG, Bärnau, Germany) was used around the prefabricated hole of the silicon mold to avoid adhesion between the veneer ceramic slurry and the custom-made silicon mold.

After gentle vibration, excess liquid was removed using tissue paper. The firing protocol for the veneer ceramic materials was followed in the furnace as per the manufacturer's instruction using Programat P310 (Ivoclar Vivadent, Schaan, Liechtenstein, Germany). A second layer of the veneer ceramic slurry was applied, following the previous mentioned process, to compensate for the shrinkage of the veneer ceramic material after the first firing cycle. Fig. 1 (A-D) demonstrates the steps of veneer ceramic cylinder fabrication and application of the load under the universal testing machine.

Shear bond strength (SBS) test was conducted. The specimens in each group ( $\mathrm{n}=30)$; GLN, GLV, SLN, and SLV were subjected to the mentioned test in different conditions. The specimens were either not stored in artificial saliva $(n=15)$ and the specimens $(n=15)$ that were immersed in artificial saliva at $37^{\circ} \mathrm{C}$ for one month. The specimens were secured on an electromechanical universal testing machine (E44.304, MTS Systems Co. Ltd., Shenzhen, China) with a special holder to conduct the test. A semicircular metal jig was positioned close to the interface between the veneer ceramic and the core at a crosshead speed of 0.5 $\mathrm{mm} / \mathrm{min}$ until failure occurred. The measured force was recorded in Newtons, and the bond strength for each core specimen was calculated by dividing the peak load in Newtons by the surface area $\left(\mathrm{mm}^{2}\right)$ to achieve the strength in $\mathrm{MPa}$. The recorded load was calculated as following: $\mathrm{b}=\mathrm{f} /$ $\mathrm{s}$ where $\mathrm{b}, \mathrm{f}$, and s represent bonding, force, and surface area, respectively.
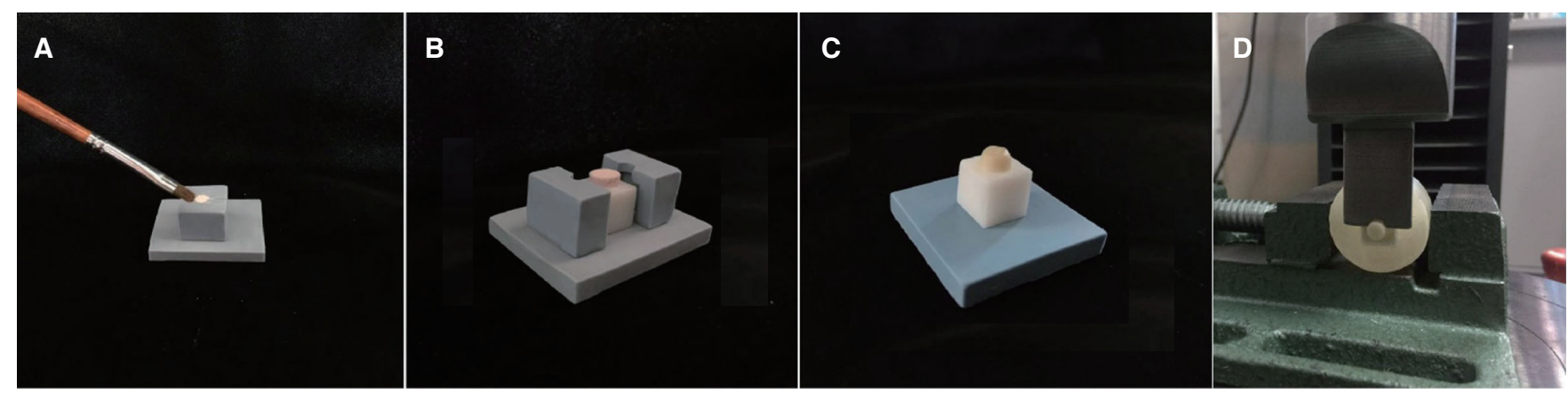

Fig. 1. Illustrating the fabrication process of veneer ceramic cylinder; the specimen seated in silicon mold with a hole on the top center to apply veneer ceramic slurry $(A)$, the specimen after applying veneer ceramic (B), the specimen after firing using furnace machine $(\mathrm{C})$, the specimen subjected to load close to interface under universal testing machine using semi-circular metal jig (D). 
Failure types were examined for the investigated specimens both visually and under stereomicroscope (Olympus SZ61, Shanghai, China). The outcomes were also examined through SEM equipped with EDS to support the failure patterns. The failure types were defined as an adhesive failure (separation of the veneer ceramic and core), cohesive failure (separation through the veneer ceramic material), and mixed type (combination of the cohesive and adhesive types). The failure types were recorded in percentages.

The results were statistically analyzed using an IBM Statistical Package for Social Sciences software (SPSS 20.0, IBM SPSS Inc., Chicago, IL, USA). The KolmogorovSmirnov normality test was applied for checking the distribution of $\mathrm{R} a$ and for SBS values, the Levene statistical test was used to test the homogeneity (equality) of variances. The Independent t-test was performed to compare the means of groups for $R a$ after the first surface treatments (grinding and sandblasting). One way ANOVA test was used to compare the means of groups for $\mathrm{R} a$ after the second surface treatment after coating the core material by veneer ceramic materials following laser scanning. The Pearson test was used to analyze correlations (r) between $\mathrm{R} a$ and shear bond strength. The chi-square test was used to compare means of failure types of studied groups. GraphPad Software Prism V.7 2016 (San Diego, CA, USA) was used to made graphs. The statistical significance was set at $\alpha=.05$.

\section{RESULTS}

Figure 2 shows the outcomes of $\mathrm{R} a$ (Fig. 2A) after the first and the second surface treatments, and SBS values (Fig. 2B) in unaged and aged conditions, respectively. The mean and standard deviation (SD) of $\mathrm{R} a$ for the first surface treatment for the grinding group was $1.05 \pm 0.24 \mu \mathrm{m}$, which was higher than the sandblasting technique $0.79 \pm 0.21 \mu \mathrm{m}$. Ra values showed a statistically significant difference between the two groups $(P<.05)$. The mean and SD of $\mathrm{R} a$ for the second surface treatment was the highest in group GLN, $1.30 \pm 0.21 \mu \mathrm{m}$, whereas the lowest value was recorded in group SLV, $0.97 \pm 0.13 \mu \mathrm{m}(P<.05)$ as shown in Fig. 2A. The shear bond strength (SBS) test values of the specimens showed a statistically significant difference between the studied groups $(P<.05)$. The specimens in group GLN showed higher values of SBS in unaged condition, i.e. before storage of specimens in artificial saliva (AS) (30.97 \pm 3.12 MPa). By contrast, the lowest value was $22.95 \pm 3.68$ $\mathrm{MPa}$ in group SLV in aged condition after the specimens were stored in AS for 1 month, and is presented in Fig. 2B.

The Pearson test between SBS and $R a$ values showed a significant positive correlation; $\mathrm{r}=+.886, P<.05$ as shown in Fig. 3A. The higher the roughness of the surfaces, the higher the SBS values are. The failure types were recorded in percentages as presented in Fig. 3B. The highest percentage of the adhesive failure type was recorded in group SLV $(36.7 \%)$, whereas the lowest value was observed in group GLN (10\%). The highest failure type in group GLN was a mixed pattern (46.7\%). A cohesive failure type $(43.3 \%)$ was detected in the mentioned group, whereas the percentage of that failure was $30,36.7,30 \%$ in SLN, GLV, and SLV groups, respectively. The chi-square test did not show a statistically significant difference in failure type patterns between the studied groups $(P=.382 ; P>.05)$.

XRD analyses did not show phase transformation after the specimens had been subjected to the first surface treatment following grinding, the prominent peaks showed tetragonal $(t)$ phase on the zirconia core material. In contrast, the sandblasting showed phase transformation from tetragonal to monoclinic, the XRD peaks are illustrated in (Fig. 4). The major peak of ( $\mathrm{t}$ ) phase was detected at $30.170^{\circ}$, which corresponded to the crystallographic plane pdf \#48-
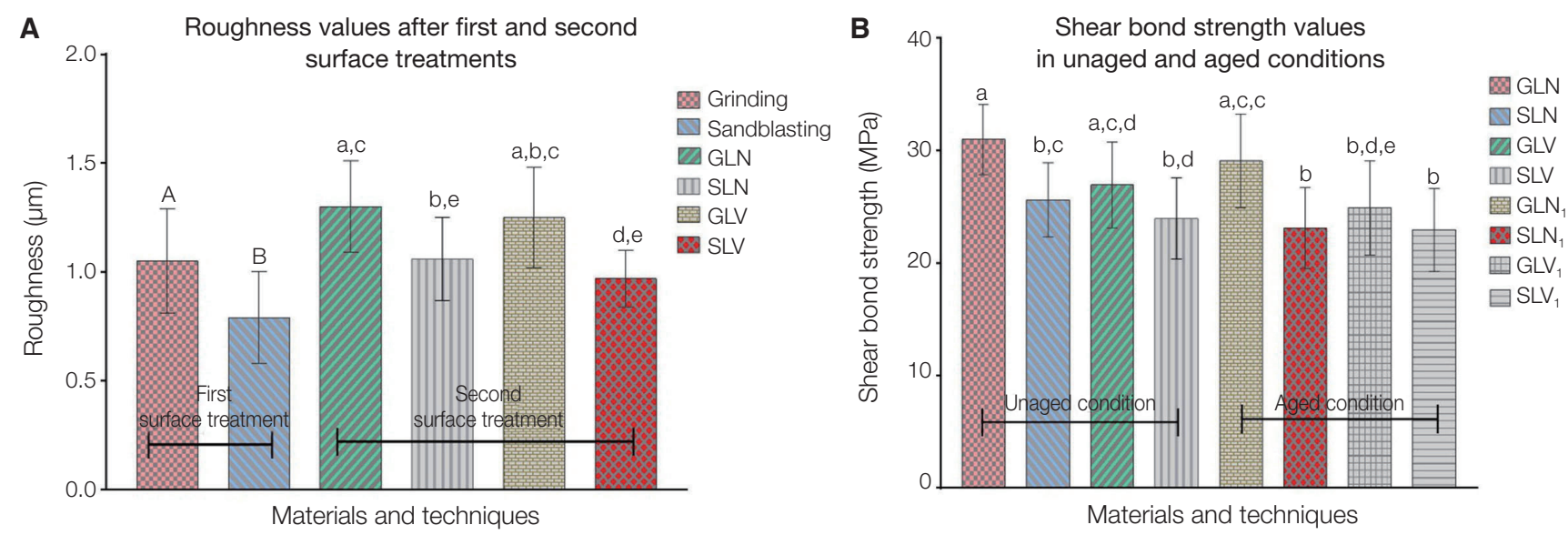

Fig. 2. Summarized outcomes of surface roughness after the first and the second surface treatments (A) and shear bond strength $(B)$, respectively. Values marked with different letters indicate statistically significant difference between the studied groups $(P<.05)$. The group names were mentioned previously. 

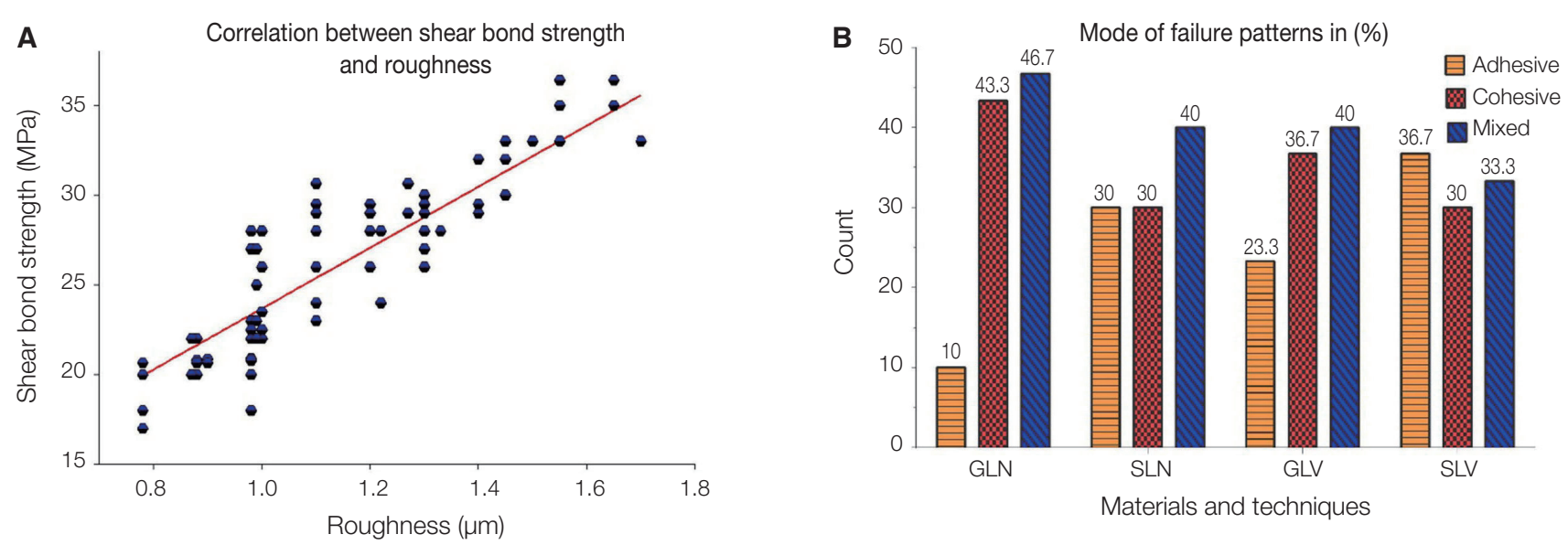

Fig. 3. Illustrates correlation between (A) and mode of failure patterns (B). The group names were mentioned previously.

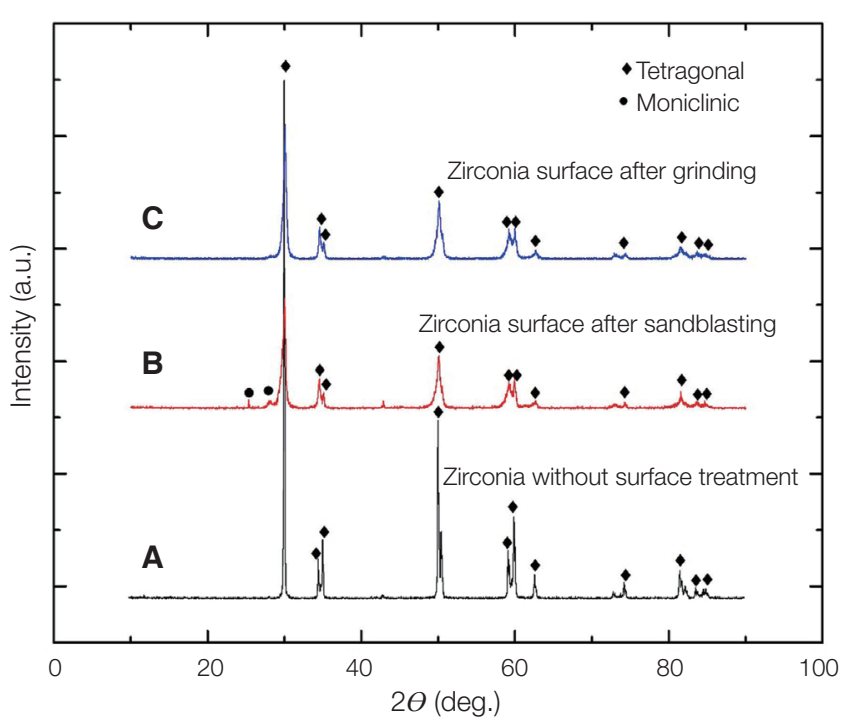

Fig. 4. XRD shows crystallographic peaks. The sole zirconia surface without coating by veneer ceramic materials $(A)$, the core material coated with veneer ceramic followed sandblasting, phase transformation was detected from $\mathrm{t}-\mathrm{m}(\mathrm{B})$, the core material coated with veneer ceramic material followed grinding technique (C).

0224. The other $(\mathrm{t})$ phases were also found at $34.742^{\circ}$, $35.278^{\circ}$, and $50.212^{\circ}$. The major peaks of the monoclinic (m) phase were found at $29.960^{\circ}$, which corresponded to the following crystallographic plane pdf \#86-1449.

The specimens' surfaces showed different roughness patterns after the first surface treatment through SEM examination as presented in Fig. 5. The grinding technique (Fig. 5A) showed higher grooves and irregularities on the surface than the sandblasting (Fig. 5B). After coating the

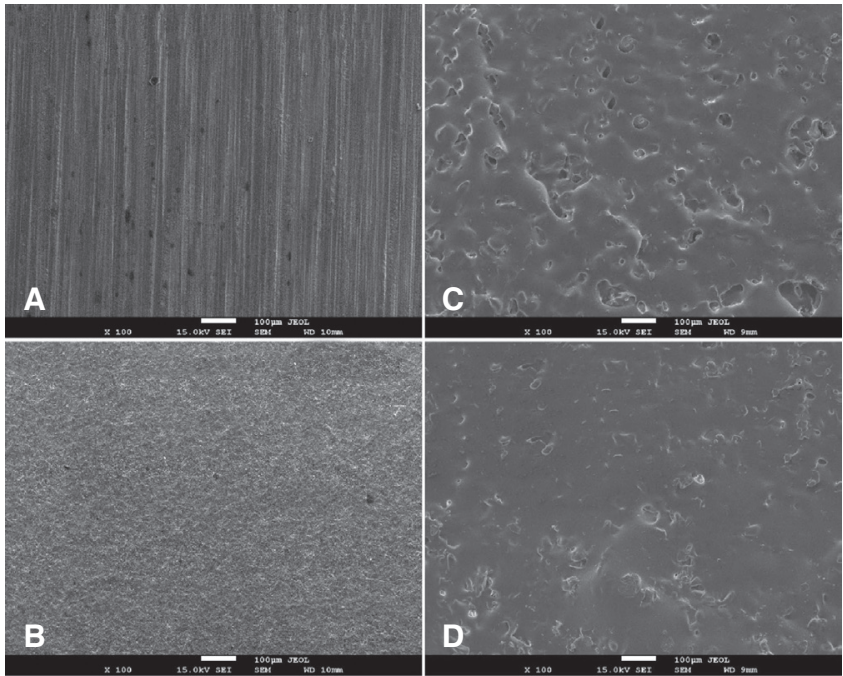

Fig. 5. SEM shows top surfaces of the zirconia core material after first $(A, B)$ and second $(C, D)$ surface treatments, respectively. (A) A specimen shows grinding as a first surface treatment. (B) A specimen shows sandblasting as a first surface treatment. (C) The specimen (A) shows deposited Noritake Cerabien ZR after laser scanning as a second surface treatment. (D) The specimen (C) shows deposited VITA VM 9 after laser scanning as a second surface treatment.

core material by veneer ceramic materials using laser scanning i.e. after the second surface treatment (Fig. 5C, 5D), the surfaces showed irregularities and certain micro-holes. In the specimens that were coated with Noritake Cerabien $\mathrm{ZR}$, the interface between the veneer ceramic and the core showed certain irregularities when first treated by grinding followed by laser scanning. In contrast, the surfaces that were treated by sandblasting followed by laser scanning showed fewer irregularities. 


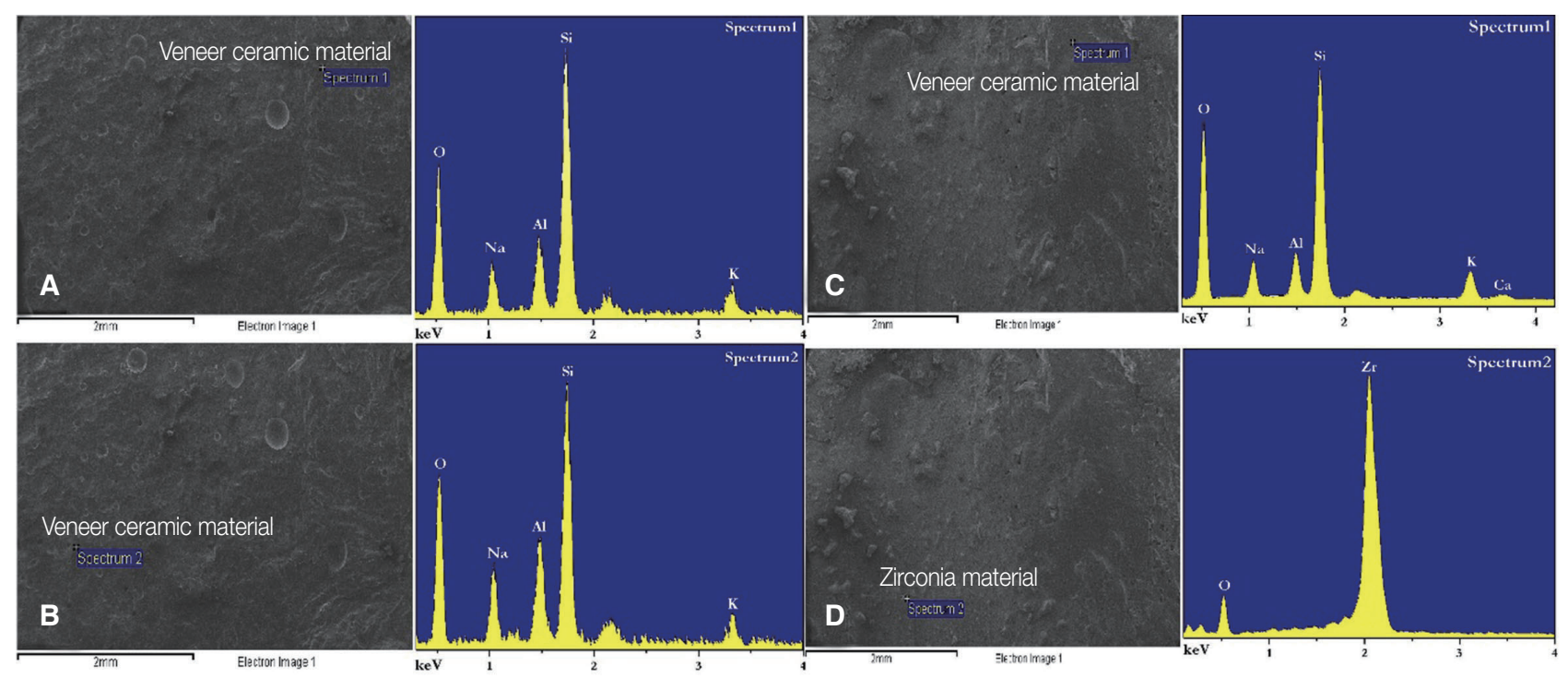

Fig. 6. Shows spot EDS analysis after conducting SBS test. The collected spectra show $\mathrm{Si}$ as prominent peaks indicating cohesive failure type (A, B); the core surface was subjected to grinding then coated by Noritake Cerabien ZR material followed by laser scanning. The collected spectra show Si and zirconia as prominent peaks in the veneer ceramic and the delaminated areas $(C, D)$, respectively; indicating a mixed failure type after the core surfaces being subjected to grinding and coated by VITA VM 9 material followed by laser scanning.

The results of line EDS analyses after the core was coated by both methods showed $\mathrm{Si}, \mathrm{Al}$, and zirconia as the most prominent components. The first two elements were the main components of the veneer ceramic, and the latter was the main component of the core material. Further, the interface also shows micro- cracks after laser scanning to coat the core surface by veneer ceramic material.

It was observed that the results of the failure types showed different patterns of failure, adhesive, cohesive and mixed, which were analyzed under stereomicroscope after conducting the shear test. A typical representation of failure types was detected and confirmed through spot EDS analysis. Figure 6 shows the spot EDS analysis for typical type of failures. The collected spectra showed $\mathrm{Si}$ and $\mathrm{Al}$ as prominent peaks, which were detected during analysis of the cohesive type of failure (Fig. 6A, 6B). However, the spot EDS analysis for mixed type showed $\mathrm{Si}$ and zirconia as prominent peaks for the veneer ceramic material and the delaminated areas, respectively (Fig. 6C, 6D).

\section{DISCUSSION}

Based on the current findings, the first hypothesis of the present study was accepted since sandblasting did not provide a better outcome than grinding followed by laser scanning. The second hypothesis was rejected as it could be observed a clear difference between the veneer ceramic materials since Noritake demonstrated improved SBS values in comparison to its counterpart in unaged and aged conditions. The principal goal of zirconia surface treatment is to enhance the mechanical properties, which could play an important role for the longevity of FPD crowns in the oral environment. ${ }^{21}$ The success rate and the longevity of the FPDs primarily depend on the integrity of the SBS between core-veneer materials; therefore, achieving sufficient bond strength is essential. ${ }^{22}$

It has been reported that the lack of bond strength between the mentioned materials resulted in delamination. ${ }^{22}$ Therefore, demonstrating an acceptable adhesion between core-veneer systems might overcome the issue. ${ }^{23}$ The assessment of the aforementioned issues through in vitro investigation could provide information to select the right core/veneer material combination to fabricate single crowns and multiple unit of the FPD crowns in load bearing areas. ${ }^{23}$

The previous clinical trial was based on different laser systems, which used higher maximum output power than that used in the current study. ${ }^{24}$ It has been reported that low output power may lead to less adverse effects on the core material than the high power. ${ }^{25}$ However, low output power may not provide adequate roughness after surface treatment. ${ }^{25}$ The difference in absorption capability from the surface of core material after surface treatment through the laser might impact on outcomes in terms of $\mathrm{R} a$ and SBS values. ${ }^{6}$ In this study, both $\mathrm{R} a$ and SBS were optimized through adequate laser energy absorption, which resulted in the improved outcomes. The Pearson test confirmed the findings of the present experimental work by providing a significant positive correlation between $\mathrm{R} a$ and SBS values. The relation between $R a$ and SBS values was proportional in such a way that the higher $\mathrm{R} a$ would lead to higher SBS values.

The current study used grinding and sandblasting tech- 
niques as the first surface treatment for the assigned specimens, and laser scanning was utilized as the second surface treatment to coat the core material by different veneer ceramic materials. Previous studies have reported different methods to treat the core materials' surface such as grinding and sandblasting, different outcomes also have been reported regarding which approach could enhance SBS values., ${ }^{7,21,26}$ The present study shows that the specimens that were treated through grinding followed by laser scanning, the 'GLN group', yielded better bond strength than sandblasting followed by the scanning process. Prior to laser scanning, the core surface material was subjected to a spraying technique to standardize specimens and allow a uniform deposition of veneer ceramic layer on the core material. The similar process was practiced in previous research. ${ }^{27,28}$ Although the current method of surface treatment was different in comparison to previous studies, the thickness of veneer ceramic could be better controlled and SBS values were optimized as well..$^{27,28}$

The outcomes of this study contradicted with previous study, the previous work showed that the sandblasting approach could demonstrate better SBS values. ${ }^{21}$ However, the present results are in agreement with another study ${ }^{29}$ that showed grinding could demonstrate higher SBS values. ${ }^{5}$ The result may be due to the fact that grinding under wet conditions using low-speed rotary instrument followed by laser scanning could preserve the structural integrity of the core material since it did not cause any phase transformation. The phase transformation from $\mathrm{t}-\mathrm{m}$ resulted from the sandblasting. The former method might lead to higher micro retention during grinding process followed by the scanning process. The SBS values were decreased significantly when the specimens were subjected to an aging condition i.e. stored in artificial saliva. The specimens belonging to GLN group, which were subjected to grinding followed by laser scanning using Noritake Cerabien ZR, could release better results than other groups such as SLN, GLV, SLV.

The impact of the sandblasting should be considered since the flaw formation on the zirconia core surface could be observed following the process and might cause phase transformation. ${ }^{26}$ Previous literature has reported the effect of sandblasting on the mechanical properties of the ceramic core..$^{30}$ A survival rate of zirconia was recorded as $90 \%$ in a 5 -year follow-up after surface modification according to the aforementioned technique. ${ }^{30}$ In addition, the surface flaws may lead to non-equilibrium of stress distribution resulting in the inadequate mechanical property of the core material through delamination in the load-bearing areas. ${ }^{31}$ As previous literature reported that $\mathrm{t}-\mathrm{m}$ phase transformation might deteriorate the survival rate of zirconia in FPDs, ${ }^{32}$ the present study was in agreement with the previous study since phase transformation was detected. The results showed that SBS values were adversely affected after specimens were subjected to the sandblasting.

In the current study, setting laser parameters played a pivotal role during the scanning process to permit adequate fusion of the veneer ceramic on the core material. In addi- tion, it was also observed that the laser beam through the laser nozzle tip, which was subjected to the core material in specified distance and speed, provided certain micro holes within the coated veneer ceramic material. These could be considered as retentive micromechanical means to yield sufficient bond strength between veneer/core materials. This finding might be due to the high output power during the scanning process.

XRD analysis did not show $\mathrm{t}-\mathrm{m}$ phase transformation following grinding. However, sandblasting presented a crystallographic change of zirconia through tetragonal to monoclinic phase transformation. It is a positive indicator of zirconia's integrity and stability, showing that conducting grinding under wet condition followed by laser scanning did not adversely impact on the core material. Nevertheless, previous studies have reported $\mathrm{t}-\mathrm{m}$ phase transformation after grinding and sandblasting. ${ }^{33,34}$ The disagreement of the current results with previous reported studies may be contributed to different methodologies which practiced by the present and previous studies.

After surface treatment and conducting SBS test, certain micro cracks could be observed at the interface of the assigned specimens in each specified group. This finding may be attributed to the fact that the core material was exposed to laser scanning and different repeated firing cycles, i.e. the first and the second firing cycles to fabricate adequate cylindrical-shape of veneer ceramic on the zirconia to perform SBS test. The present work is in agreement with previous literature since conducting SBS test detected the existence of the microcracks at the interface.

This might due to the maximizing internal pressure which was exerted during the load application. ${ }^{35}$

In this study, the specimens in the GLN group showed the highest percentages of cohesive and mixed failure types (43.3, 46.7\%, respectively) in comparison to other groups. Meanwhile, the SLN and SLV groups presented the lowest value $(30.0 \%)$ of cohesive failure type and the lowest value $(40.0,33.3 \%)$ of mixed pattern, respectively. In addition, the highest percentage of the adhesive failure type was observed in the SLV group (36.7\%). In contrast, the GLN group recorded the lowest value (10\%) of the similar failure pattern. The GLV group was considered the second lower value presenting cohesive and mixed failure types (36.7, $40.0 \%$, respectively). It is been reported that a cohesive failure type might be a positive indicator for the existence of adequate bond strength between veneer/core materials. ${ }^{36}$ The presence of such cohesive failure as the highest percentage in groups GLN and GLV might be due to the change in the physical properties, such as fusion at veneer/ core interface. The specimens subjected to grinding followed by laser scanning provided better outcomes since the failure types could be considered as a confirmation, and the failure types among all groups are demonstrated in Fig. 3B. The adhesive and mixed failure types could be considered inferior to cohesive type since the former two types were presenting the higher percentages of delamination on the core surface than the latter. It is worthy to note that the 
mixed failure could be better than adhesive failure as the remaining attached veneer ceramic on the zirconia core showed a higher percentage in the former type. This may be interpreted as an adequate interlocking between veneer/core material since, in cohesive failure, the fractured line passing through veneer ceramic cylinder and the core surface was covered with a layer of veneer ceramic material. This may reflect to have an acceptable bond strength and a successful fusion between materials.

An adhesive fracture, which was recorded as the most frequent failure (36.7\%) among SLV specimens might result from insufficient bond strength between the veneer/core materials. Sandblasting might adversely affect the core surface specimens in terms of showing lower mechanical properties, i.e. decreasing SBS values. The finding could also be due to the mismatch of the coefficient of thermal expansion (CTE) between the veneer/core ceramic materials used in SLV group. It has been reported that the thermal mismatch lower than $1 \times 10^{-6} \mathrm{~K}^{-1}$ is compatible and is less susceptible to crack formation following sintering. ${ }^{37}$ The current work used different materials as veneer and core ceramic materials (Noritake Cerabien ZR, VITA VM 9, and zirconia core), and the CTE values of the mentioned materials based on the manufacturer's data were reported as 9.5 $\pm 0.25 \times 10^{-6} \mathrm{~K}^{-1}, 9.2 \times 10^{-6} \mathrm{~K}^{-1}$, and $10.5 \pm 0.5 \times 10^{-6} \mathrm{~K}^{-1}$, respectively.

Different elemental compositions have been observed through EDS analyses after coating the core by veneer ceramic and conducting the SBS test. The results presented silica as the most prominent peak in the areas coated by the veneer ceramic. In particular, this could be detected in the specimens that showed cohesive failure types (Fig. 6A, 6B). However, the silica and zirconia could demonstrate prominent peaks in specimens that presented mixed failure types (Fig. 6C, 6D). The results could be attributed to the fact that the variation in elemental composition and microstructure of the veneer/core materials might result in achieving satisfied bond strength. In addition, the interlocking mechanism may increase the bond strength through chemical bonding and micromechanical interaction between the materials.

The limitations of the study could be summarized into certain aspects as the study did not use or perform the followings: different laser types, control group, thermocycling test, fracture strength or toughness of core material after surface treatments, fatigue tolerance property of the core material, flexural strength, and possible changes in chemical compositions of veneer/core materials. Therefore, the future experimental works might further focus on these points after surface treatment of zirconia for fixed partial denture crowns.

\section{CONCLUSION}

Within the limitation of the current study, the following conclusions could be drawn:

Grinding followed by laser scanning could provide better shear bond strength values than sandblasting followed by laser scanning. Noritake Cerabien ZR veneer ceramic material could demonstrate better performance than VITA VM 9 in terms of recording better fusion property to the core material by yielding better shear bond strength values. A positive correlation was recorded between surface roughness and the shear bond strength values. Laser scanning optimized bond strength between veneer/core ceramic materials as a second surface treatment. The structural integrity of zirconia (tetragonal) was preserved through grinding under a wet condition with low rotary speed followed by laser scanning, not through sandblasting followed by laser scanning; the latter technique demonstrated monoclinic phase after the first surface treatment.

\section{ACKNOWLEDGEMENTS}

The authors would like to express their heartfelt gratitude to the Chinese Scholarship Council (CSC) for financial support throughout the study. The authors would also like to acknowledge Northeastern University and Qing Mei Dental Laboratory Technology Co., Ltd in Shenyang, China to provide help during performing the experimental work.

\section{ORCID}

Adil Othman Abdullah https://orcid.org/0000-0002-6230-323X Yu Hui https://orcid.org/0000-0002-7380-1314

Xudong Sun https://orcid.org/0000-0002-2001-7972

Sarah Pollington https://orcid.org/0000-0001-5669-7933

Fenik Kaml Muhammed https://orcid.org/0000-0002-5591-8260

Yi Liu https://orcid.org/0000-0002-3278-8803

\section{REFERENCES}

1. Her SB, Kim KH, Park SE, Park EJ. The effect of zirconia surface architecturing technique on the zirconia/veneer interfacial bond strength. J Adv Prosthodont. 2018;10:259-64.

2. Gehrke P, Tabellion A, Fischer C. Microscopical and chemical surface characterization of CAD/CAM zircona abutments after different cleaning procedures. A qualitative analysis. J Adv Prosthodont 2015;7:151-9.

3. Eisenmenger-Sittner C, Nöbauer C, Mozetic M, Kovač J, Zaplotnik R. Stabilization of tetragonal $\mathrm{ZrO} 2$ by oxygen plasma treatment of sputtered $\mathrm{ZrCu}$ and $\mathrm{ZrAl}$ thin films. Surf Coat Technol 2018;347:270-7.

4. Ural Ç, Külünk T, Külünk Ş, Kurt M. The effect of laser treatment on bonding between zirconia ceramic surface and resin cement. Acta Odontol Scand 2010;68:354-9.

5. Mosharraf R, Rismanchian M, Savabi O, Ashtiani AH. Influence of surface modification techniques on shear bond strength between different zirconia cores and veneering ceramics. J Adv Prosthodont 2011;3:221-8.

6. Abd El-Ghany OS, Sherief AH. Zirconia based ceramics, some clinical and biological aspects: Review. Future Dent J 2016;2:55-64.

7. Yamaguchi H, Ino S, Hamano N, Okada S, Teranaka T. Examination of bond strength and mechanical properties of 
Y-TZP zirconia ceramics with different surface modifications. Dent Mater J 2012;31:472-80.

8. Tarib NA, Anuar N, Ahmad M. Shear bond strength of veneering ceramic to coping materials with different pre-surface treatments. J Adv Prosthodont 2016;8:339-44.

9. Cho JH, Kim SJ, Shim JS, Lee KW. Effect of zirconia surface treatment using nitric acid-hydrofluoric acid on the shear bond strengths of resin cements. J Adv Prosthodont 2017;9: 77-84.

10. Khayat W, Chebib N, Finkelman M, Khayat S, Ali A. Effect of grinding and polishing on roughness and strength of zirconia. J Prosthet Dent 2018;119:626-31.

11. Miyazaki T, Nakamura T, Matsumura H, Ban S, Kobayashi T. Current status of zirconia restoration. J Prosthodont Res 2013;57:236-61.

12. de Lima E, Meira J, Ozcan M, Cesar P. Chipping of veneering ceramics in zirconium dioxide fixed dental prosthesis. Curr Oral Health Rep 2015;2:169-73.

13. Marefati MT, Hadian AM, Hooshmand T, Yekta BE, Koohkan R. Wettability of zirconia by feldspathic veneer in dental restorations: Effect of firing atmosphere and surface roughness. Ceram Int 2018;44:4307-12.

14. Koenig V, Vanheusden AJ, Le Goff SO, Mainjot AK. Clinical risk factors related to failures with zirconia-based restorations: an up to 9-year retrospective study. J Dent 2013;41:1164-74.

15. Agustín-Panadero R, Román-Rodríguez JL, Ferreiroa A, SoláRuíz MF, Fons-Font A. Zirconia in fixed prosthesis. A literature review. J Clin Exp Dent 2014;6:e66-73.

16. Soon G, Pingguan-Murphy B, Lai KW, Akbar SA. Review of zirconia-based bioceramic: Surface modification and cellular response. Ceram Int 2016;42:12543-55.

17. Kasraei S, Atefat M, Beheshti M, Safavi N, Mojtahedi M, Rezaei-Soufi L. Effect of surface treatment with carbon dioxide (CO2) laser on bond strength between cement resin and zirconia. J Lasers Med Sci 2014;5:115-20.

18. Shukla PP, Lawrence J. Evaluation of fracture toughness of $\mathrm{ZrO} 2$ and Si3N4 engineering ceramics following CO2 and fibre laser surface treatment. Opt Lasers Eng 2011;49:229-39.

19. Mirhashemi A, Sharifi N, Moharrami M, Chiniforush N. Evaluation of different types of lasers in surface conditioning of porcelains: A review article. J Lasers Med Sci 2017;8:10111.

20. ISO 4288. Geometrical Product Specifications (GPS)-Surface Texture: Profile method-Rules and procedures for the assessment of surface texture. International Standards Organization (ISO); Geneva; Switzerland, 1996.

21. Kirmali O, Akin H, Ozdemir AK. Shear bond strength of veneering ceramic to zirconia core after different surface treatments. Photomed Laser Surg 2013;31:261-8.

22. Wang G, Zhang S, Bian C, Kong H. Effect of zirconia surface treatment on zirconia/veneer interfacial toughness evaluated by fracture mechanics method. J Dent 2014;42:808-15.

23. Yoon HI, Yeo IS, Yi YJ, Kim SH, Lee JB, Han JS. Effect of surface treatment and liner material on the adhesion between veneering ceramic and zirconia. J Mech Behav Biomed Mater 2014;40:369-74.

24. Stübinger S, Homann F, Etter C, Miskiewicz M, Wieland M,
Sader R. Effect of Er:YAG, CO(2) and diode laser irradiation on surface properties of zirconia endosseous dental implants. Lasers Surg Med 2008;40:223-8.

25. Ural C, KalyoncuoĞlu E, Balkaya V. The effect of different power outputs of carbon dioxide laser on bonding between zirconia ceramic surface and resin cement. Acta Odontol Scand 2012;70:541-6.

26. El-Shrkawy Z, El-Hosary M, Saleh O, Mandour M. Effect of different surface treatments on bond strength, surface and microscopic structure of zirconia ceramic. Future Dent J 2016;2:41-53.

27. Muhammed F, Pollington S, Xudong S, Abdullah A, Liu Y. Novel coatings on zirconia for improved bonding with veneer ceramics. Coatings 2018;8:363.

28. Farhan FA, Sulaiman E, Kutty MG. Effect of new zirconia surface coatings on the surface properties and bonding strength of veneering zirconia substrate. Surf Coat Technol 2018;333:247-58.

29. Qeblawi DM, Muñoz CA, Brewer JD, Monaco EA Jr. The effect of zirconia surface treatment on flexural strength and shear bond strength to a resin cement. J Prosthet Dent 2010; 103:210-20.

30. Sasse M, Kern M. CAD/CAM single retainer zirconia-ceramic resin-bonded fixed dental prostheses: clinical outcome after 5 years. Int J Comput Dent 2013;16:109-18.

31. Kosmac T, Oblak C, Jevnikar P, Funduk N, Marion L. Strength and reliability of surface treated Y-TZP dental ceramics. J Biomed Mater Res 2000;53:304-13.

32. Monaco C, Tucci A, Esposito L, Scotti R. Microstructural changes produced by abrading Y-TZP in presintered and sintered conditions. J Dent 2013;41:121-6.

33. Ryan DPO, Fais LMG, Antonio SG, Hatanaka GR, Candido LM, Pinelli LAP. Y-TZP zirconia regeneration firing: Microstructural and crystallographic changes after grinding. Dent Mater J 2017;36:447-53.

34. Tada K, Sato T, Yoshinari M. Influence of surface treatment on bond strength of veneering ceramics fused to zirconia. Dent Mater J 2012;31:287-96.

35. Kim JW, Covel NS, Guess PC, Rekow ED, Zhang Y. Concerns of hydrothermal degradation in CAD/CAM zirconia. J Dent Res 2010;89:91-5.

36. Fischer J, Grohmann P, Stawarczyk B. Effect of zirconia surface treatments on the shear strength of zirconia/veneering ceramic composites. Dent Mater J 2008;27:448-54.

37. Steiner PJ, Kelly JR, Giuseppetti AA. Compatibility of ceramic-ceramic systems for fixed prosthodontics. Int J Prosthodont 1997;10:375-80. 